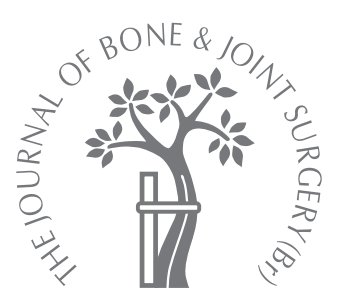

T. Kubo,

T. Sugita,

S. Shimose,

T. Matsuo,

K. Arihiro,

M. Ochi

From Hiroshima

University,

Hiroshima, Japan

\title{
Expression of hypoxia-inducible factor- $1 \alpha$ and its relationship to tumour angiogenesis and cell proliferation in cartilage tumours
}

\author{
E. Kubo, MD, PhD, Assistant \\ Professor, Orthopaedic \\ Surgeon \\ S. Shimose, MD, PhD \\ Assistant Professor, \\ Orthopaedic Surgeon \\ - T. Matsuo, MD, PhD, \\ Assistant Professor, \\ Orthopaedic Surgeon \\ M. Ochi, MD, PhD, Professor \\ and Chairman, Orthopaedic \\ Surgeon \\ Department of Orthopaedic \\ Surgery \\ K. Arihiro, MD, PhD, \\ Associate Professor \\ Pathologist \\ Department of Anatomical \\ Pathology \\ Graduate School of Biomedical \\ Sciences, Hiroshima \\ University, 1-2-3 Kasumi, \\ Minami-ku, Hiroshima, 734- \\ 8551, Japan
}

T. Sugita, MD, PhD, Director, Orthopaedic Surgeon

Department of Orthopaedic

Surgery

Hiroshima Prefecture Hospital

1-5-54 Ujinakanda, Minami-ku,

Hiroshima, 734-8530, Japan.

Correspondence should be sent to $\operatorname{Dr}$ T. Kubo; e-mail:

kubot@hiroshima-u.ac.jp

()2008 British Editorial Society of Bone and Joint Surgery doi:10.1302/0301-620X.90B3 $19806 \$ 2.00$

J Bone Joint Surg [Br] 2008;90-B:364-70.

Received 8 June 2007;

Accepted after revision 30

October 2007

\begin{abstract}
We investigated the use of hypoxia-inducible factor (HIF) proteins as prognostic markers in chondrosarcoma and the relationship of HIF to the biological characteristics of cartilage tumours. The expression of HIF-1 $\alpha$, HIF- $2 \alpha$, proliferating cell nuclear antigen (PCNA) and microvessel density (MVD) were measured immunohistochemically in 29 specimens of cartilage tumour.

There was no HIF- $1 \alpha$ and HIF-2 $\alpha$ staining in any of the nine benign cartilage tumours. In 20 specimens of chondrosarcoma, the rate of HIF- $1 \alpha$ and HIF- $2 \alpha$ expression was $40 \%$ and $25 \%$, respectively. The tumour size ( $\geq 8 \mathrm{~cm}$ ), histological grade (grade 2 and grade 3 ) surgical margin (marginal and intralesional) and HIF-1 $\alpha$ expression (positive) correlated significantly with a shorter disease-free survival. There was a significant association between HIF-1 $\alpha$ and the MVD and a strong trend towards a correlation between HIF-1 $\alpha$ and the PCNA index or histological grade.

Our findings suggest that HIF-1 $\alpha$ protein may be a useful objective marker in the assessment of the prognosis in chondrosarcoma, since it plays an important role in tumour angiogenesis and cell proliferation.
\end{abstract}

Chondrosarcomas are generally resistant to radio- and chemotherapy which means that surgical wide resection is the only curative treatment. The rates of local recurrence, distant metastases and survival vary from study to study. Consequently, the histological grade of cartilage tumours has traditionally been regarded as the best tool for the assessment of prognosis. ${ }^{1}$ However, the histological determination of the grade of the tumour is basically subjective and pathologists do not always agree on the number or appearance of cytological factors in chondrosarcoma cells. ${ }^{2}$ It is often difficult to distinguish between lowgrade chondrosarcoma and benign processes such as enchondromas and osteochondromas. Moreover, it is of critical importance to differentiate accurately between low- and intermediategrade chondrosarcomas because orthopaedic surgeons are beginning to treat low-grade chondrosarcomas in long bones with intralesional procedures and local adjuvants. More elaborate objective methods have been sought to assess prognosis.

It has long been suspected that hypoxia is involved in many pathophysiological processes including neoplasm and inflammation. It is also the prime stimulus for angiogenesis, which is probably one of the key elements involved in the initiation and development of tumours. ${ }^{3}$ Hypoxia may play an even more significant role in the evolution of cartilage tumours than in others because of the phenotypic links between cartilage tumour and cartilage which is hypoxic and avascular. ${ }^{4}$

One of the key regulators of the cellular response to hypoxic stimuli is the transcription factor hypoxia-inducible factor (HIF). ${ }^{3}$ The HIF-1 is a heterodimer composed of HIF- $1 \alpha$ and HIF-1 $\beta$ subunits. The latter is continuously expressed while HIF- $1 \alpha$ accumulates rapidly within the nuclei of the hypoxic cells, primarily because of the prevention of ubiquitination and proteasomal degradation of the protein which usually take place in normoxic cells. The HIF-1 $\alpha$ heterodimer activates the transcription of many genes which code for proteins involved in angiogenesis, glucose metabolism, cell proliferation and invasion. Recently, other members of the family have been described. ${ }^{5-7}$ HIF- $1 \alpha$ and HIF- $2 \alpha$ are thought to play a significant role in tumour angiogenesis, are widely expressed by various cancers and have been shown to be significant prognostic markers in selected cancers. ${ }^{5-7}$ Although the expression of HIF- $1 \alpha$ in cartilage tumours has been investigated, ${ }^{4,8}$ the precise correlation of HIF-1 $\alpha$ expression with clinico- 
pathological features and the overall impact on prognosis has not been evaluated in patients with chondrosarcoma.

We have examined the immunohistochemical expression of HIF- $1 \alpha$ and HIF- $2 \alpha$ proteins in surgical specimens of chondrosarcoma to evaluate the prognostic importance of this expression. In addition, HIF- $1 \alpha$ expression was also analysed and compared with the microvessel density (MVD) and the proliferating cell nuclear antigen (PCNA) index.

\section{Materials and Methods}

We obtained 29 specimens of cartilage tumour from patients treated at our institution between 1986 and 2001. Written informed consent was obtained for participation in the study from all the patients or their guardians.

Slides of each specimen which had been stained with haematoxylin and eosin were reviewed to confirm the diagnosis and histological grade of each tumour using currentlyaccepted criteria. ${ }^{9,10}$ Blocks containing specific features of chondrosarcoma were selected. An appropriate histological grade was assigned in a blinded fashion by two authors (TK, KA), one of whom was a bone pathologist (KA). In particular, grade-1 chondrosarcoma was distinguished from enchondroma by its growth pattern. ${ }^{10}$ Enchondroma is characterised by islands of tumour cartilage surrounded by trabecular bone and/or osteoid, whereas the tumour cartilage of chondrosarcoma infiltrates the marrow spaces and involves the trabecular bone.

There were 20 specimens of chondrosarcoma and nine of benign cartilage neoplasia. According to the histological grade 14 chondrosarcomas were grade 1 , three were grade 2 , and three grade 3 (which included one dedifferentiated chondrosarcoma and one mesenchymal chondrosarcoma). Of the benign cartilage tumours three were enchondromas, three were osteochondromas and three were chondroblastomas.

Immunohistochemical staining. Each tissue block was cut into sections $5 \mu \mathrm{m}$ in thickness, transferred to Matsunami adhesive silan (MAS)-coated glass slides (Matsunami, Osaka, Japan), deparaffinised in xylene, rehydrated in a graded series of decreasing ethanol concentrations and then rinsed in tris-buffered saline Tween-20 (TBST) (50 mM Tris/HC1 pH 7.6, containing $0.3 \mathrm{M}$ sodium chloride and $0.1 \%$ Tween 20 ). For the detection of HIF-1 $\alpha$ and HIF- $2 \alpha$, sections were immersed in Target Retrieval Solution (DakoCytomation Inc., Carpinteria, California), and placed in a hot-water bath for 20 minutes. After antigen retrieval, there followed a cooling-off period of 20 minutes. Sections were immunostained using the Catalysed Signal Amplification system (DakoCytomation Inc.) according to the manufacturer's instructions. The HIF-1 $\alpha$ antibody (ESEE122, diluted 1:1000; Novus Biological Inc., Littleton, Colorado) and HIF- $2 \alpha$ antibody (Ep190b, 1:1000; Novus Biological Inc.) were incubated with the tissue sections overnight at $4^{\circ} \mathrm{C}$ in a moisture chamber. Target Retrieval Solution (DakoCytomation Inc.) was used for the detection of cluster of differentiation (CD34), whereas the antigen retrieval procedure was omitted for the detection of PCNA. CD34 antibody (Ready-to use Nseries Qbend 10, DakoCytomation Inc.) and PCNA antibody (Ready-to use N-series PC10, DakoCytomation Inc.) were incubated with the tissue sections for 30 minutes at room temperature in a moisture chamber, and then the polymer-peroxidase method was used (EnVision+/HRP, DakoCytomation Inc.). The reaction products were visualised by exposing the sections to 3,3-diaminobenzidine. Nuclei were lightly counterstained for about ten seconds with Gill's formulation \#2 haematoxylin. Tissue sections of renal-cell carcinoma with strong nuclear HIF- $1 \alpha$ expression were used as a positive control group. Nonspecific reactivity was assessed by omission of the primary antibody and the specificity was confirmed in the tumour section as well as in the control tissue by preabsorption of the antisera by blocking peptide supplied by the manufacturer.

Immunohistochemical evaluation. Two independent observers (TK, KA) evaluated stained specimens in a blinded fashion. Each score was discussed by all the authors to reach an overall consensus. Cells were considered to be immunoreactive to HIFs when distinct nuclear staining was identified. Cytoplasmic staining, observed occasionally, was ignored because active HIFs are located only in the nucleus. The extent of staining was scored as follows: (-) indicating a negative reaction of the tumour cells; $( \pm)$ nuclear staining in $<10 \%$ of cells; $(+) 10 \%$ to $50 \%$ of cells; and $(++)>50 \%$ of cells. For all analyses, the tumours in which stained tumour cells made up $>10 \%$ of the tumour were regarded as positive.

For the evaluation of proliferating tumour cells, we examined at least 500 tumour cells to determine whether their nuclei were positive for PCNA staining. We did not divide the PCNA expression level. Instead we used the percentage of PCNA-positive cells (PCNA index) for all analyses. ${ }^{11}$ The PCNA index was classified as high if it was $\geq 12.6 \%$, a figure representing the median value.

Microvessel counting. Angiogenic activity was assessed by estimating CD34-positive microvessels in the surrounding stroma of invasive tumour nests. ${ }^{12}$ In each tumour, hot-spot areas displaying the highest vessel density were identified by scanning tumour sections at low-power magnification $(\times 40)$. The maximum vessel density was determined from these hot-spot areas at fields under high-power field (HPF) magnification $(\times 400)$, and the mean of the counts for the three fields was calculated. Identification of the lumen of a vessel was not necessary for a structure to be defined as a vessel. The MVD was classified as high if it was $\geq 12.9 / \mathrm{HPF}$, a figure representing the median value.

The time of follow-up was calculated from the date of the operation. The median follow-up was for 78 months (1 to 192 ).

Statistical analysis. All survival analyses were evaluated using the Kaplan-Meier method and the log-rank test. The 


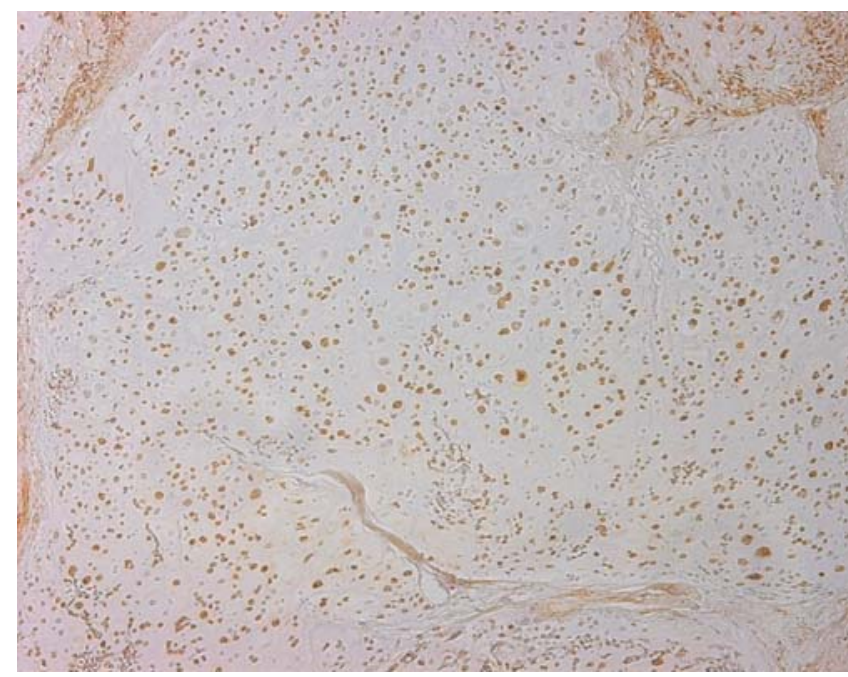

Fig. 1a

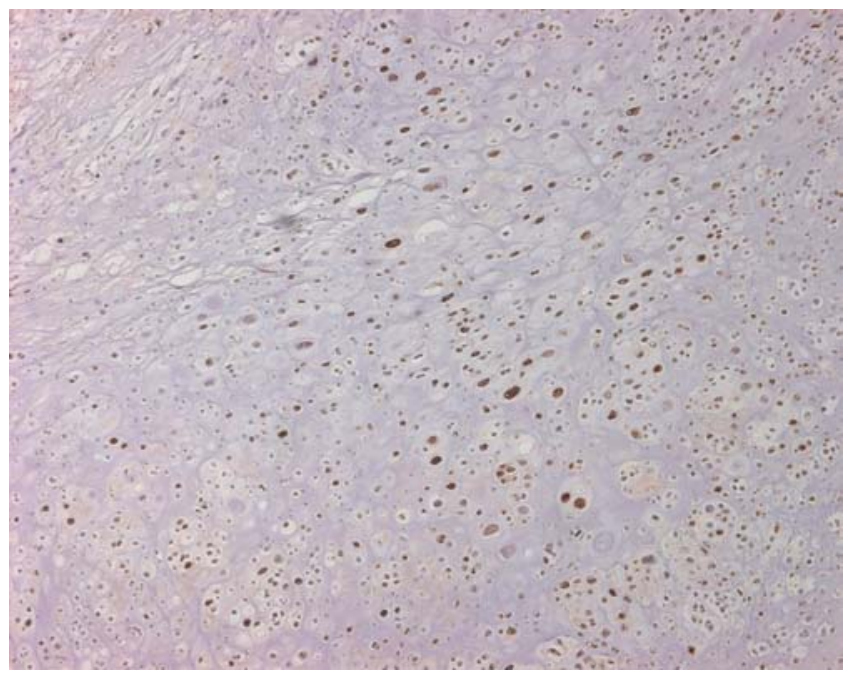

Fig. 1b

Photomicrographs showing the immunohistochemistry of a) hypoxia-inducible factor (HIF)-1 $\alpha$ and b) HIF-2 $\alpha$ in a grade-3 chondrosarcoma of the proximal tibia. Representative chondrosarcoma tissues with $(++)$ staining show dark brown nuclear staining of HIF- $1 \alpha$ and HIF-2 $\alpha$ in a diffuse fashion $(x$ 100).

correlation of HIF-1 $\alpha$ expression with the MVD, PCNA index and histological grade was analysed using Fisher's exact test and the chi-squared test. All analyses were performed by SPSS software (SPSS Inc., Chicago, Illinois) and Statcel (OMS Ltd, Saitama, Japan). A p-value $<0.05$ was considered to be significant.

\section{Results}

HIF- $1 \alpha$ and HIF- $2 \alpha$ expression in cartilage tumours. There was no HIF- $1 \alpha$ and HIF- $2 \alpha$ staining in any of the nine benign cartilage tumours. In eight $(40 \%)$ of the 20 specimens of chondrosarcoma, HIF- $1 \alpha$ expression was positive, with five $(25 \%)$ strongly expressing the protein $(++)$. In five $(25 \%)$ specimens HIF-2 $\alpha$ expression was positive, with only two $(10 \%)$ strongly expressing the protein $(++)$. All HIF- $2 \alpha$-positive specimens showed positive HIF- $1 \alpha$ staining. Representative immunostains of HIF-1 $\alpha$ and HIF-2 $\alpha$ are shown in Figure 1.

Survival analysis in chondrosarcomas. None of the patients with chondrosarcoma presented with metastases. The median age at the time of surgery was 42 years (15 to 71 ). There were eight men and 12 women. Their tumours were sited in the trunk in 12 ( 9 pelvis, 1 rib, 1 scapula and 1 vertebra) and in the limbs in eight (4 tibia, 3 humerus and 1 femur). The median tumour size, defined as the maximum diameter of the resected tumour was $11.7 \mathrm{~cm}$ (4 to 27). A total of 16 patients were treated by wide excision, two by marginal excision, and two by intralesional excision. There was one local recurrence and three patients developed pulmonary metastases. The other 16 patients remained free from disease. The five- and ten-year disease-free survival rates were $81.3 \%$ and $63.2 \%$, respectively.
The tumour size $(\geq 8 \mathrm{~cm})$, histological grade (grade 2 and grade 3 ), the surgical margin (marginal and intralesional) and HIF- $1 \alpha$ expression (positive), correlated significantly with a shorter disease-free survival $(\mathrm{p}=0.020,0.033,0.017$ and 0.020, respectively; Table I and Figure 2).

Correlation of HIF- $1 \alpha$ with the MVD, PCNA and histological grade. In order to investigate the effect of HIF- $1 \alpha$ on tumour angiogenesis and cell proliferation, the relationship of HIF- $1 \alpha$ to the MVD, PCNA index and histological grade was analysed in the 20 chondrosarcomas. Of the 29 patients in the study, four $(13.8 \%)$ showed a high MVD and five $(17.2 \%)$ had a high PCNA index. Representative immunostains of CD34 and PCNA are shown in Figure 3. There was a significant correlation of HIF- $1 \alpha$ expression with the MVD (Fisher's exact and chi-squared tests, $\mathrm{p}=0.014$ and $\mathrm{p}=0.006$, respectively; Table II). Although neither the PCNA index nor histological grade significantly correlated with HIF-1 $\alpha$ expression, both showed a strong trend towards significance (Fisher's exact test). This trend could achieve significance using the chi-squared test (PCNA, $\mathrm{p}=0.035$; histological grade, $\mathrm{p}=0.035$; Table II). This could be explained by the results of inadequate numbers for statistical power. Two non-conventional chondrosarcomas, one dedifferentiated chondrosarcoma and one mesenchymal chondrosarcoma strongly expressed HIF-1 $\alpha$ and HIF- $2 \alpha$ proteins $(++)$.

\section{Discussion}

In recent years it has been thought that the expression of HIF- $1 \alpha$ and HIF- $2 \alpha$ may be a useful prognostic indicator for a variety of malignancies. ${ }^{5-7}$ Zhong et al ${ }^{13}$ observed that HIF- $1 \alpha$ expression also occurred in premalignant lesions 
Table I. Prognostic variables in chondrosarcoma as determined by univariate analysis of diseasefree survival (DFS)

\begin{tabular}{|c|c|c|c|}
\hline Variable & 5-year DFS (\%) (n = 20) & $95 \%$ confidence interval & p-value \\
\hline \multicolumn{4}{|l|}{ Age (yrs) } \\
\hline$<40$ & 71 & 38 to 100 & 0.468 \\
\hline$\geq 40$ & 89 & 68 to 100 & \\
\hline \multicolumn{4}{|l|}{ Gender } \\
\hline Male & 70 & 34 to 100 & 0.216 \\
\hline Female & 89 & 68 to 100 & \\
\hline \multicolumn{4}{|l|}{ Tumour size $(\mathrm{cm})$} \\
\hline$<8$ & 100 & 0 to 100 & 0.020 \\
\hline$\geq 8$ & 66 & 34 to 98 & \\
\hline \multicolumn{4}{|l|}{ Tumour site } \\
\hline Extremity & 100 & 0 to 100 & 0.861 \\
\hline Trunk & 66 & 34 to 98 & \\
\hline \multicolumn{4}{|l|}{ Histological grade ${ }^{9,10}$} \\
\hline 1 & 93 & 79 to 100 & 0.033 \\
\hline 2 and 3 & 50 & 1 to 99 & \\
\hline \multicolumn{4}{|l|}{ Surgical margin } \\
\hline Wide & 84 & 64 to 100 & 0.017 \\
\hline Intralesional and marginal & 75 & 33 to 100 & \\
\hline \multicolumn{4}{|l|}{$\mathrm{HIF}^{*}-1 \alpha$ expression } \\
\hline Negative & 91 & 74 to 100 & 0.020 \\
\hline Positive & 66 & 25 to 100 & \\
\hline
\end{tabular}

such as colonic adenoma, breast ductal carcinoma in situ and prostatic intra-epithelial neoplasia, but not in benign tumours, suggesting that HIF-1 $\alpha$ expression may take place in the very early stages of carcinogenesis. To date, only two studies have evaluated the expression of HIF- $1 \alpha$ in cartilage tumours. ${ }^{4,8}$ They found no staining in benign tumours but there was HIF-1 $\alpha$ expression in all grades of chondrosarcoma at similar levels which increased significantly in angiogenic tumours. They could not correlate HIF- $1 \alpha$ expression with other clinicopathological features or survivorship. In our study, HIF-1 $\alpha$ and HIF-2 $\alpha$ were not expressed in any of the benign cartilage tumours, which is consistent with the previous studies. However, in chondrosarcoma, the rate of expression of HIF- $1 \alpha$ and HIF- $2 \alpha$ was $40 \%$ and $25 \%$, respectively, which does not accord with the previous studies. The discrepancy may have been the result of different methods of evaluating the positivity of HIF- $1 \alpha$ staining. In the previous studies ${ }^{4,8}$ HIF- $1 \alpha$ expression was evaluated within the nucleus and cytoplasm by the staining intensity and number of tumour cells. Our analysis was based only on the nuclear expression since it can be assumed that nuclear HIF-1 $\alpha$ protein is the active form. ${ }^{13,14}$ In fact, Nakanishi et $\mathrm{al}^{15}$ found that despite a significant correlation between HIF- $1 \alpha$ protein expression and disease-free survival in transitional cell carcinomas of the upper urinary tract, the expression of HIF- $1 \alpha$ mRNA was not associated either with progression or prognosis, proba- bly because its mRNA expression would not be correlated with the active form of nuclear HIF- $1 \alpha$ protein. In addition to previously reported prognostic factors, such as the surgical margin, tumour size and histological grade, the active form of HIF-1 expression may help to predict a group of chondrosarcoma patients with a poor prognosis.

The two most important characteristics of malignant tumours are their unrestrained growth and their capacity to produce metastases. The ability to induce sustained angiogenesis is needed for both. Until now, only two studies have shown that cartilage tumours can possess microvessels in their development and progression, and that their vascularity correlates with the grade of tumour. ${ }^{16,17}$ We have, in addition, demonstrated a significant correlation between HIF-1 $\alpha$ expression and a high MVD, suggesting that hypoxia in the microenvironment of the tumour may be involved in angiogenesis in chondrosarcoma.

It is increasingly thought that hypoxia is not the only factor to stimulate HIF-1 activity after the induction of angiogenesis. For example, Feldser et $\mathrm{al}^{18}$ reported that in the treatment of cultured prostatic carcinoma cells with insulin, insulin-like growth factor (IGF)-1, or IGF-2 induced the expression of HIF- $1 \alpha$ protein, which in turn required the expression of IGF-2 mRNA, suggesting the involvement of HIF- $1 \alpha$ protein in an autocrine growth factor loop. Zhong et $\mathrm{al}^{13}$ also reported that HIF-1 $\alpha$ overexpression was associated with aberrant accumulation of 


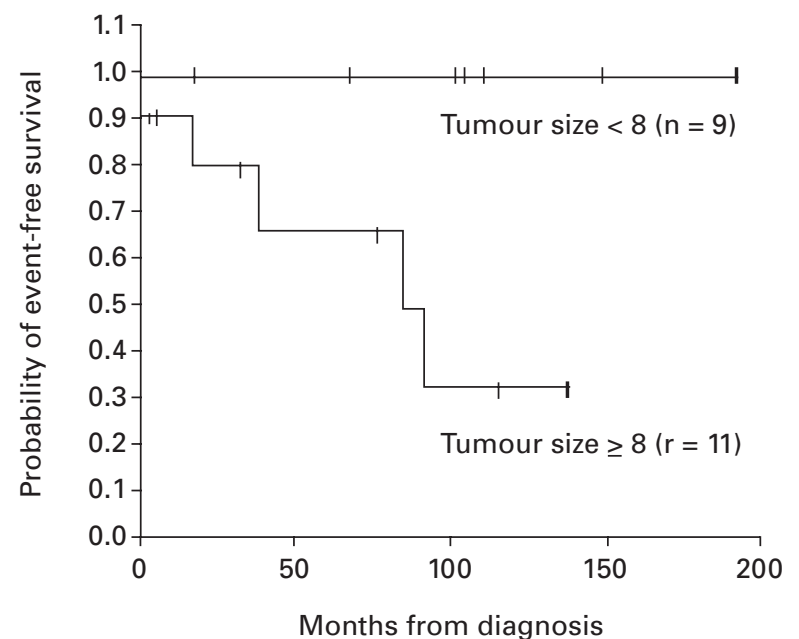

Fig. 2a

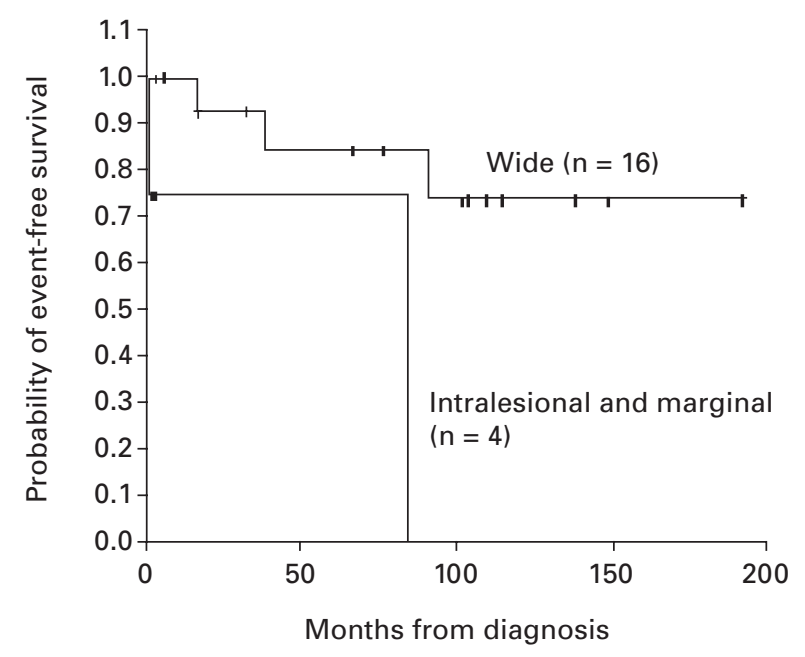

Fig. 2c

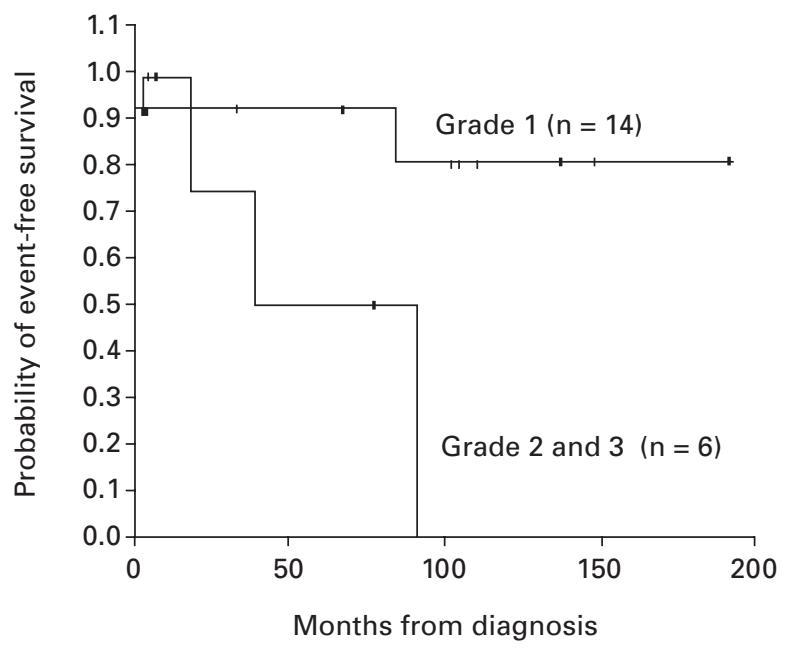

Fig. $2 b$

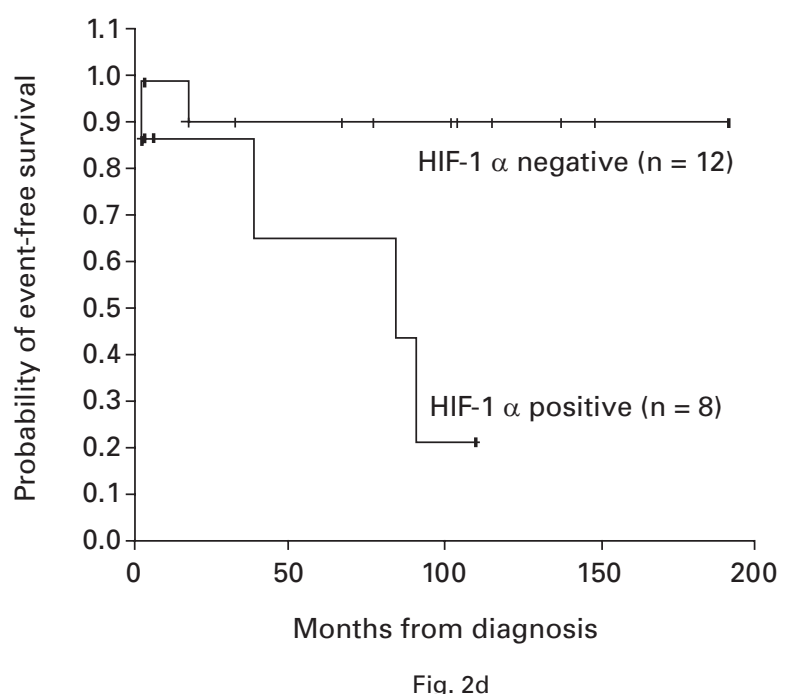

Fig. 2d

Graphs showing Kaplan-Meier event-free survival for chondrosarcoma according to a) tumour size, b) histological grade, c) surgical margin and d) hypoxia-inducible factor (HIF)- $1 \alpha$ expression. The vertical bars indicate the censored patients (no relapse).

p53 oncogene in 75 human cancers, including most cancers of the colon and breast. We used PCNA to explain the relationship between $\mathrm{HIF}-1 \alpha$ and the proliferation of chondrosarcoma cells, since PCNA is an assistant factor of DNA synthetase, takes part in DNA biological synthesis and regulates the cell cycle and cell proliferation by tetramer with cyclin, cyclin-dependent kinase (CDK) and p21. ${ }^{19}$ Our immunohistochemistry revealed that the expression of HIF- $1 \alpha$ positively correlated with the PCNA index of chondrosarcoma cells, indicating the presence of HIF- $1 \alpha$ in actively proliferating cells, which is in line with other studies. ${ }^{20-22}$

Surgical treatment with wide resection is the mainstay of treatment for chondrosarcoma. There is no widely accepted adjuvant therapy and chemo- and radiotherapy have a minimal role. Lin et $\mathrm{al}^{4}$ reported that when chondrosarcoma cells were transfected with small interfering RNA targeting HIF- $1 \alpha$ before exposure to hypoxia, HIF$1 \alpha$ protein and the angiogenic cytokin vascular endothelial growth factor (VEGF) mRNA decreased. They speculated that anti-angiogenic treatment strategies which target the HIF- $1 \alpha$ and VEGF pathways may be worth exploring as experimental therapy for chondrosarcoma. In fact, several HIF inhibitors, including topotecan, 17$\mathrm{N}$-allylamino-17-demethoxygeldanamycin, 2-methoxyestradiol and small molecules targeting receptor tyrosine kinase-dependent signalling pathways are currently in clinical development for the treatment of 


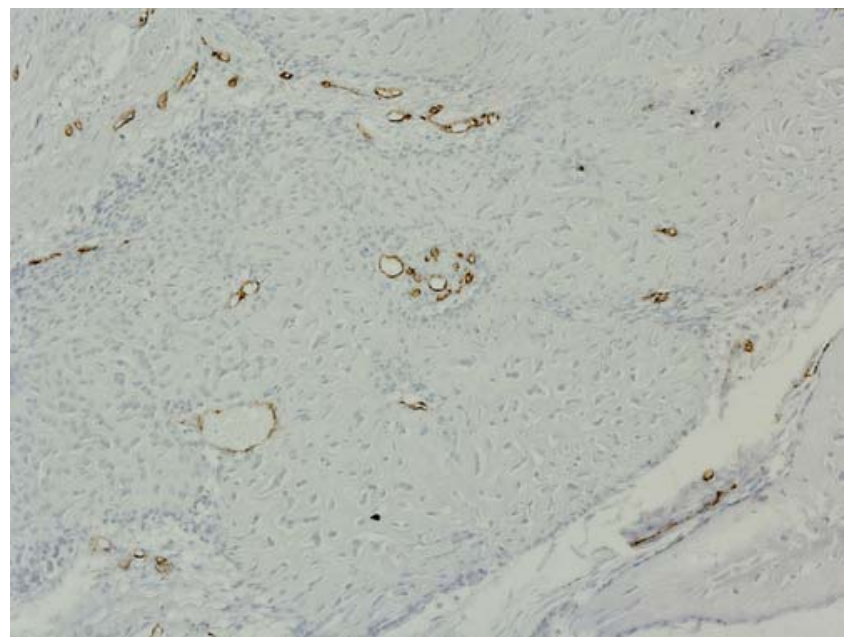

Fig. 3a

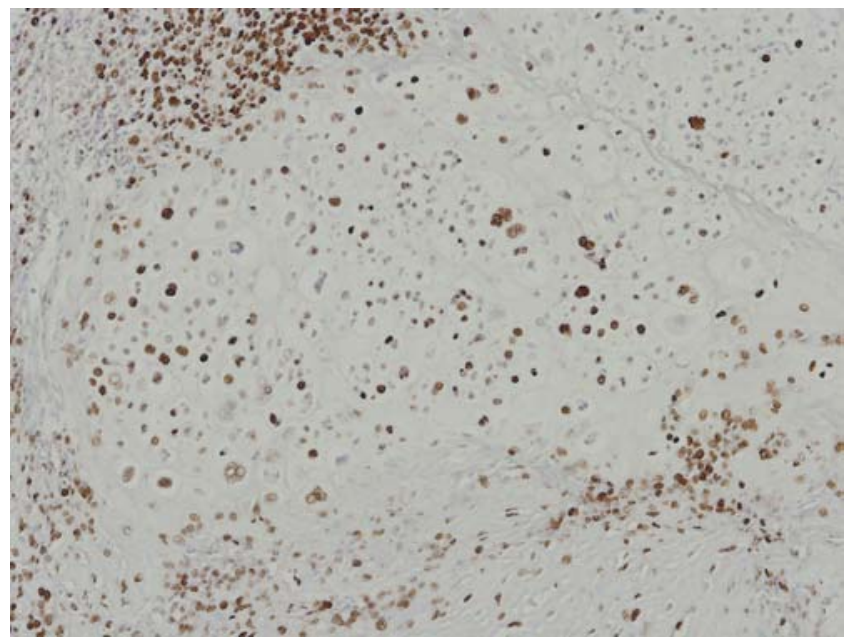

Fig. $3 b$

Photomicrographs showing the immunohistochemistry of a) cluster of differentiaton (CD) 34 and b) proliferating cell nuclear antigen (PCNA) in the case shown in Figure 1. Representative chondrosarcoma tissue has CD34-positive microvessels in the interfaces between tumour nests and stroma and diffuse strong positivity for PCNA in the nuclei of the cells $(\times 100)$.

\begin{tabular}{|c|c|c|c|c|}
\hline \multirow[b]{2}{*}{ Variable } & \multicolumn{2}{|c|}{ HIF-1 $\alpha$ expression } & \multicolumn{2}{|l|}{ p-value } \\
\hline & Positive & Negative & Fisher's exact test & chi-squared test \\
\hline \multicolumn{5}{|l|}{ MVD } \\
\hline Low & 4 & 12 & 0.014 & 0.006 \\
\hline High & 4 & 0 & & \\
\hline \multicolumn{5}{|l|}{ PCNA } \\
\hline Low & 4 & 11 & 0.058 & 0.035 \\
\hline High & 4 & 1 & & \\
\hline \multicolumn{5}{|c|}{ Histological grade } \\
\hline 1 & 3 & 10 & 0.052 & 0.035 \\
\hline 2 and 3 & 5 & 2 & & \\
\hline
\end{tabular}

cancers. ${ }^{23}$ Our findings are of value for the development of anti-angiogenic chemotherapy for patients with chondrosarcoma.

In conclusion, our study has shown that the active form of HIF- $1 \alpha$ expression is associated with diminished disease-free survival and correlates with the MVD and PCNA index, suggesting that HIF- $1 \alpha$ may play an important role in tumour angiogenesis and cell proliferation in chondrosarcoma. The active form of HIF-1 $\alpha$ expression may be a more objective marker than the histological grade in the assessment of the prognosis of chondrosarcoma.

No benefits in any form have been received or will be received from a commercial party related directly or indirectly to the subject of this article.

\section{References}

1. Rizzo M, Ghert MA, Harrelson JM, Scully SP. Chondrosarcoma of bone: analysis of 108 cases and evaluation for predictors of outcome. Clin Orthop 2001;391:224-33.

2. Welkerling H, Krats S, Ewerbeck V, Delling G. A reproducible and simple grading system for classical chondrosarcomas: analysis of 35 chondrosarcomas and 16 enchondromas with emphasis on recurrence rate and radiological and clinical data. Virchows Arch 2003;443:725-33.

3. Dachs GU, Patterson AV, Firth JD, et al. Targeting gene expression to hypoxic tumor cells. Nat Med 1997;3:515-20.

4. Lin C, McGough R, Aswad B, Block JA, Terek R. Hypoxia induces HIF-1alpha and VEGF expression in chondrosarcoma cells and chondrocytes. J Orthop Res 2004;22:1175-81.

5. Yoshimura H, Dhar DK, Kohno H, et al. Prognostic impact of hypoxia-inducible factors 1alpha and 2alpha in colorectal cancer patients: correlation with tumor angiogenesis and cyclooxygenase-2 expression. Clin Cancer Res 2004;10:8554-60.

6. Hui EP, Chan AT, Pezzella F, et al. Coexpression of hypoxia-inducible factors 1alpha and 2alpha, carbonic anhydrase IX, and vascular endothelial growth factor in nasopharyngeal carcinoma and relationship to survival. Clin Cancer Res 2002;8:2595-604.

7. Sivridis E, Giatromanolaki A, Gatter KC, Harris AL, Koukourakis MI. Tumor and Angiogenesis Research Group: association of hypoxia-inducible factors 1alpha and 2alpha with activated angiogenic pathways and prognosis in patients with endometrial carcinoma. Cancer 2002;95:1055-63. 
8. McGough RL, Lin C, Meitner P, Aswad BI, Terek RM. Angiogenic cytokines in cartilage tumors. Clin Orthop 2002;397:62-9.

9. Evans HL, Ayala AG, RomsdahI MM. Prognostic factors in chondrosarcoma of bone: clinicopathologic analysis with emphasis on histologic grading. Cancer 1977;40:818-31.

10. Mirra JM, Gold R, Downs J, Eckardt JJ. A new histologic approach to the differentiation of enchondroma and chondrosarcoma of the bones: a clinicopathologic analysis of 5 cases. Clin Orthop 1985;201:214-37.

11. Lee $\mathbf{C H}$, Lee $\mathbf{M K}$, Kang CF, et al. Differential expression of hypoxia inducible factor-1 alpha and tumor cell proliferation between squamous cell carcinomas and adenocarcinomas among operable non-small cell lung carcinomas. J Korean Med Sci2003;18:196-203.

12. Weidner N, Semple JP, Welch WR, Folkman J. Tumor angiogenesis and metastasis: correlation in invasive breast carcinoma. N Engl J Med 1991;324:1-8.

13. Zhong H, De Marzo AM, Laughner E, et al. Overexpression of hypoxia-inducible factor 1alpha in common human cancers and their metastases. Cancer Res 1999;59:5830-5.

14. Beasley NJ, Leek R, Alam M, et al. Hypoxia-inducible factors HIF-1alpha and HIF2alpha in head and neck cancer: relationship to tumor biology and treatment outcome in surgically resected patients. Cancer Res 2002;62:2493-7.

15. Nakanishi K, Hiroi S, Tominaga S, et al. Expression of hypoxia-inducible factor1alpha protein predicts survival in patients with transitional cell carcinoma of the upper urinary tract. Clin Cancer Res 2005;11:2583-90.
16. Ayala G, Liu C, Nicosia R, Horowitz S, Lackman R. Microvasculature and VEGF expression in cartilaginous tumors. Hum Patho/ 2000;31:341-6.

17. McGough RL, Aswad BI, Terek RM. Pathologic neovascularisation in cartilage tumors. Clin Orthop 2002;397:76-82.

18. Feldser D, Agani F, lyer NV, et al. Reciprocal positive regulation of hypoxia-inducible factor 1alpha and insulin-like growth factor 2. Cancer Res 1999;59:3915-18.

19. Kelman Z. PCNA: structure, functions and interactions. Oncogene 1997;14:629-40.

20. Kronblad A, Jirström K, Rydén L, Nordenskjöld B, Landberg G. Hypoxia inducible factor-1alpha is a prognostic marker in premenopausal patients with intermediate to highly differentiated breast cancer but not a predictive marker for tamoxifen response. Int J Cancer 2006;118:2609-16.

21. Bos R, Zhong $\mathbf{H}$, Hanrahan $\mathbf{C F}$, et al. Levels of hypoxia-inducible factor-1 alpha during breast carcinogenesis. J Natl Cancer Inst 2001;93:309-14.

22. Wei H, Wang C, Chen L. Proliferating cell nuclear antigen, survivin, and CD34 expressions in pancreatic cancer and their correlation with hypoxia-inducible factor 1alpha. Pancreas 2006;32:159-63.

23. Melillo G. Inhibiting hypoxia-inducible factor 1 for cancer therapy. Mol Cancer Res 2006;4:601-5. 